\title{
Application of Green Building Materials and Multi-objective Energy-Saving Optimization Design
}

\author{
Zhaoran Liu*, An Guo \\ Department of Arts and Media, Xingtai Polytechnic College, Xingtai 054000, China
}

Corresponding Author Email: liuzhaoran01@ 163.com

https://doi.org/10.18280/ijht.390133

Received: 29 October 2020

Accepted: 5 January 2021

\section{Keywords:}

green building materials, energy-saving

design, multi-objective optimization

\begin{abstract}
Green building materials have brought fundamental changes to the traditional construction methods, enabling better environmental protection and energy-saving performance of the buildings. However, due to the various material types and the large property differences, until now there isn't a uniform evaluation index system (EIS) for green building materials, the existing studies on the green-level evaluation of green building materials during production and use are insufficient, and the research on energy-saving design is just getting started. For this reason, this paper attempted to launch a research on the multi-objective energy-saving optimization design of buildings based on the application of green building materials. First, the quantification method for the environmental impact factors of green building materials was elaborated, and the intervals and standards of the quantification evaluation were given; then, a green building material optimization selection model was constructed, and a multi-objective energy-saving optimization algorithm was proposed; at last, experimental results gave the green levels of a few candidate green building materials and the scores of the environmental impact factors, which had verified the effectiveness of the proposed algorithm.
\end{abstract}

\section{INTRODUCTION}

According to the 2019 China Energy Statistics Yearbook, the total energy consumption of the construction industry throughout the year is about 1.43 billion tons of standard coal, which is more than a quarter of the total final energy consumption of China [1-3]. In recent years, as the concept of sustainable development has been put forward, the energysaving of buildings has gradually transformed to green buildings, and the industry of green building materials has ushered in a fast growth [4-6]. Green building materials can achieve the environmental protection and energy-saving goals by employing new science and technology means, and they have brought fundamental changes to the traditional construction methods, in this way, the issues of building energy-saving, environmental protection, and pollution control have been well integrated [7, 8].

Field scholars have made great progress in the application of green building materials [9-12]. With the rapid development of the building materials industry, new-type construction and decoration materials have emerged in large quantity, and some of them have brought serious threat to the indoor environment and human health [13, 14]. Lee [15] took 7 kinds of building materials including sanitary ceramics, mortar, concrete, energy-saving glass, ceramic tiles, masonry materials, and thermal insulation materials as the research objects, and established a practical comprehensive evaluation system for green building materials based on life cycle assessment and life cycle cost analysis [16]. According to the requirements for building materials in terms of production technology, properties, input and output costs, and environmental impact, Kaur et al. [17] evaluated the green property of building material products using a AHP-based fuzzy comprehensive evaluation method; in order to improve the accuracy and discriminability of weight coefficients and index values, they adopted a fixed index scale to construct the judgement matrix and comprehensively evaluated 8 types of representative green building materials. Affected by processing techniques and production output, the prices of most green building materials are higher, and their market acceptance willingness is generally low, therefore it's necessary to comprehensively consider the economy and energy efficiency to better promote the application of green building materials [18-21]. Regarding the construction of evaluation systems for green building materials, Berseneva et al. [22] proposed a specific core index evaluation method based on single-factor evaluation and a full life cycle evaluation method based on fuzzy comprehensive evaluation; through a green evaluation case analysis, they obtained the final green levels of green building materials, and improved the operability and discriminability of the evaluation. For the definition and purpose of green building materials, Ilham et al. [23] established a promotion evaluation model for green building materials based on fuzzy evaluation and TOPSIS method, and comprehensively considered the influence of value factors such as use value, economic value and environmental value on the promotion of green building materials. Pioppi et al. [24] introduced green building materials and green building technologies into the construction of energy-saving campus, the involved green building materials mainly included aerated concrete blocks, high-strength steel bars and high-performance concrete, inorganic thermal insulation mortar, foam glass, heatinsulating multi-cavity sealed metal window frames, and highefficiency energy-saving lamps, etc.; and the involved green 
building technologies mainly included roof greening, ground source heat pump (GSHP) and air source heat pump (ASHP) heating systems, integrated sun shading design, independent temperature and humidity control air conditioning system, and real-time visualized building energy consumption measurement, etc. Echeverria et al. [25] optimized the cost and energy efficiency of composite heat-insulating concreate blocks via the aspects of insulation layer thickness and block wall thickness, and verified the thermal performance of the blocks through energy-saving experiments.

At present, the green building materials are of diverse types and different properties, so the evaluation focuses are quite different, and until now there isn't a unified EIS for green building materials, which has caused certain difficulties for the selection, optimization, and energy-saving design of green building materials. At the same time, the existing studies on the green-level evaluation of green building materials during production and use are insufficient, and the research on energy-saving design is just getting started. For this reason, this paper conducted a research on the application of green building materials and the multi-objective energy-saving optimization design. The main content of this paper includes the following aspects: 1) the quantification method of the environmental impact factors of green building materials was elaborated, and the green levels of the materials were analyzed based on calculation results; 2) the intervals and standards of the quantification evaluation of green building materials were given; 3 ) a green building material optimization and selection model was constructed, a multi-objective energy-saving optimization algorithm was proposed, and the flow of the algorithm was introduced; 4) experimental results gave the green levels of a few candidate green building materials and the scores of the environmental impact factors, which had verified the effectiveness of the proposed algorithm.

\section{QUANTIFICATION OF ENVIRONMENTAL IMPACT FACTORS OF GREEN BUILDING MATERIALS AND THE EVALUATION OF GREEN LEVELS}

Under normal circumstances, a same-type environmental impact may be caused by different factors; for each environmental impact type, an index value could be set to calculate the environmental impact potential values of the different environmental impact factors. This paper adopted the equivalent factor method to calculate the environmental impact potential values of different environmental impact factors, and further obtained the comprehensive environmental loads of each environmental impact type. In the following paragraphs, the specific calculation method of the environmental impact potential values of green building materials during production and use will be introduced.

Non-renewable resources such as ore, fossil fuels, and land are resources without biological characteristics. Assume $T_{c}$ represents the total consumption of non-renewable resources during the production and use of green building materials; $p_{i}$ represents the consumption of the $i$-th resource of the green building materials in the inventory analysis; and $\delta_{c i}$ represents the equivalent limestone coefficient of the $i$-th resource; then, the total consumption of non-renewable resources during the production and use of green building materials can be expressed by Formula 1:

$$
T_{c}=\sum_{i=1}^{n} p_{i} \delta_{c i}
$$

Energy consumption refers to the comprehensive consumption of primary energy, secondary energy, nonrenewable energy and renewable energy during the production, construction, transportation, utilization, and treatment processes of green building materials. Assume $\delta_{d i}$ represents the standard coal coefficient of the $i$-th energy source; $R_{D}$ represents the total energy consumption during the production and use of green building materials; $d_{i}$ represents the energy consumption of the $i$-th energy source of the green building materials in the inventory analysis; and $\delta_{d i}$ represents the equivalent standard coal coefficient of the $i$-th resource; then, the total energy consumption of the green building materials during production and use can be calculated by Formula 2:

$$
R_{D}=\sum_{i=1}^{n} d_{i} \delta_{d i}
$$

The space occupied by solid construction wastes buried underground or put in garbage landfills is the consumption of space resources. Assume $\rho_{i}$ and $M_{i}$ are the density and mass of the i-th solid construction waste; $V_{T}$ represents the total space resource consumption of solid construction wastes generated during the production and use of green building materials; it can be expressed by Formula 3 as:

$$
V_{T}=\sum_{i=1}^{n} M_{i} / \rho_{i}
$$

The greenhouse effect is mainly caused by greenhouse gases in the atmosphere, they absorb long-wave radiations from the earth surface, causing them unable to smoothly penetrate the atmosphere. Assume $E_{\mathrm{CO} 2}$ represents the equivalent weight of $\mathrm{CO}_{2}$ produced during the production and use of green building materials; $A_{i}$ and $H N Q_{i}$ respectively represent the i-th greenhouse gas's inventory analysis volume and global warming potential value; Formula 4 gives the calculation method for the type of factors related to global warming during the production and use of green building materials, see below:

$$
E_{C O_{2}}=\sum_{i=1}^{n} H N Q_{i} A_{i}
$$

If acidic substances are discharged during the production and use of green building materials, acidification effect and acid rain will be generated, $\mathrm{SO}_{2}$ is the reference data of such acidification effect, and it can be described by the acidification potential value. Assume $E_{S O 2}$ represents the equivalent weight of $\mathrm{SO}_{2}$ during the production and use of green building materials; $A_{i}$ and $S N_{i}$ respectively represent the i-th acidic substance's inventory analysis volume and acidification potential value during the production and use of green building materials; Formula 5 gives the calculation method for the type of factors related to the acidification effect during the production and use of green building materials, see below: 


$$
E_{S O_{2}}=\sum_{i=1}^{n} S N_{i} A_{i}
$$

The ozone layer in the stratosphere can absorb ultraviolet light. If ozone-depleting substances that can damage the ozone layer are emitted during the production and use of green building materials, the earth's ecological environment will be damaged by ultraviolet rays. Assume $E_{C F C-11}$ represents the equivalent weight of $C F C$-11 during the production and use of green building materials; $A_{i}$ and $E H_{i}$ respectively represent the $i$-th ozone-depleting substance's inventory analysis volume and depletion potential value; Formula 6 below gives the calculation method for the type of factors related to ozone depletion during the production and use of green building materials:

$$
E_{C F C-11}=\sum_{i=1}^{n} E H_{i} A_{i}
$$

Photochemical smog is the product of oxidation reactions between $N O_{x}$ and volatile solvent under the action of sunlight. Assume $E_{\mathrm{C} 2 \mathrm{H} 4}$ represents the equivalent weight of $\mathrm{C}_{2} \mathrm{H}_{4}$ during the production and use of green building materials; $A_{i}$ and $V O S_{i}$ respectively represent the $i$-th volatile organic compound's inventory analysis volume and photochemical smog potential value; then, the type of factors related to photochemical smog can be calculated by Formula 7:

$$
E_{C_{4} H_{4}}=\sum_{i=1}^{n} \operatorname{VOS}_{i} A_{i}
$$

Nutrients such as phosphorus and nitrogen in the industrial wastewater can accelerate the proliferation of aquatic fungi and microorganisms in the water body, which would result in a decrease in the content of dissolved oxygen in the water and causing eutrophication to the water body. Assume $E_{P O 43}$ represents the equivalent weight of $\mathrm{PO}_{4}{ }^{3-}$ during the production and use of green building materials; $A_{i}$ and $L V A_{i}$ respectively represent the $i$-th nutrient's inventory analysis volume and eutrophication potential value; then the type of factors related to water body eutrophication can be calculated by Formula 8 as:

$$
E_{\mathrm{PO}_{4}{ }^{3-}}=\sum_{i=1}^{n} L V A_{i} A_{i}
$$

Based on the above analysis of the potential values of various types of environmental impact during the production and use of green building materials, this paper selected the green-level evaluation indexes of green building materials and constructed the evaluation space for the corresponding production and use processes. Assume $R_{\max }$ and $R_{\min }$ are the upper and lower limits of the evaluation standards. First, according to the relevant national industry norms or standards, the national statistical yearbooks, and the relevant research results, an evaluation space with the value range of (Rmin, Rmax) was constructed and divided into three sub-intervals of $\left(0, R_{\min }\right],\left(R_{\min }, R_{\max }\right]$, and $\left(R_{\max }, \infty\right)$. Because the value range is the entire range of positive real numbers, the green-level divisions for the various green building materials become more distinguishable. Table 1 gives the divided quantitative evaluation intervals of green building materials.

If the evaluation index is a cost-type quantitative index, the evaluation interval $\left(R_{\min }, R_{\max }\right)$ can be divided into equal $m-2$ parts; at the same time, order $R_{\max }$ be $R_{1}$ and $R_{\min }$ be $R_{m-1}$; then, the value of the lower limit $R_{j}$ of the interval corresponding to the $j$-th level can be calculated by Formula 9:

$$
R_{j}=R_{j-1}-\left(R_{1}-R_{m-1}\right) /(m-2)
$$

If the evaluation index is a benefit-type quantitative index; order $R_{\min }$ be $R_{1}$ and $R_{\max }$ be $R_{j-1}$. At this time, the value of the lower limit $R_{j}$ of the interval corresponding to the $\mathrm{j}$-th level can be calculated by Formula 10:

$$
R_{j}=R_{j-1}+\left(R_{m-1}-R_{1}\right) /(m-2)
$$

If $R_{\min }$ is equal to 0 , Formula 9 and Formula 10 can be modified as follows:

$$
\begin{aligned}
& R_{j}=R_{j-1}-\left(R_{1}-R_{j-1}\right) /(m-1) \\
& R_{j}=R_{j-1}+\left(R_{\mathrm{j}-1}-R_{1}\right) /(m-1)
\end{aligned}
$$

\begin{tabular}{|c|c|c|c|c|c|}
\hline \multirow{2}{*}{$\begin{array}{c}\text { Level } \\
\text { Unqualified }\end{array}$} & \multicolumn{3}{|c|}{$\begin{array}{l}\text { Cost-type quantitative index; Benefit-type } \\
\text { quantitative index }\end{array}$} & \multirow{2}{*}{$\begin{array}{c}\begin{array}{c}\text { Standard } \\
\text { range }\end{array} \\
{[0,1.5]}\end{array}$} & \multirow{2}{*}{$\begin{array}{l}\text { Description } \\
\text { Does not reach the qualified level in the industry }\end{array}$} \\
\hline & $\left(R_{1}, \infty\right)$ & & $\left(0, R_{1}\right)$ & & \\
\hline Level A & & {$\left[R_{1}, R_{2}\right)$} & & $(1.5,2.5]$ & Reach the qualified level in the industry \\
\hline Level B & & {$\left[R_{1}, R_{2}\right)$} & & $(2.5,3.25]$ & Reach the medium level in the industry \\
\hline Level C & & {$\left[R_{1}, R_{2}\right)$} & & $(3.25$ & Reach the leading level in the industry \\
\hline Level D & $\left(R_{4}, 0\right)$ & & $\left(R_{4}, \infty\right)$ & {$[4.25,5]$} & Reach the top level in the industry \\
\hline
\end{tabular}

Table 2 shows the quantitative evaluation standards of green building materials proposed in this paper.

Table 1. Quantitative evaluation intervals of green building materials

\begin{tabular}{cccccc}
\hline Level & Unqualified & Level A & Level B & Level C & Level D \\
\hline Interval & {$[0,1.5]$} & $(1.5,2.5]$ & $(2.5,3.25]$ & $(3.25,4.25]$ & {$[4.25,5]$} \\
\hline
\end{tabular}

Table 2. Quantitative evaluation standards for green building materials 


\section{CONSTRUCTION OF OPTIMIZATION SELECTION MODEL FOR GREEN BUILDING MATERIALS}

Through the calculation of environmental impact potential values during the production and use of green building materials and the discussion and analysis on the evaluation interval division of green building materials in the previous section, this paper chose to use the material optimization selection method that is most suitable for the evaluation standards and evaluation space of green building materials to construct the corresponding mathematical model.

Taking the different environmental impact potential value variables as the objective function variables, the objective function and the corresponding constraints that keep the production and use costs of green building materials at the minimum level could be constructed. Assume $N_{\mathrm{z}}$ represents the number of types of candidate green building materials; the quantity, demand, price, and use proportion of each-type candidate material are represented by $N_{\mathrm{s}}, Q_{j i}, J_{j i}$, and $S_{j i}$, respectively, wherein $j \in N_{\mathrm{z}}, i \in N s$, then the constructed objective function can be expressed as:

$$
W=\operatorname{Min} \sum_{j \in N_{\mathrm{z}}} \sum_{i \in N_{s}} Q_{j i} * J_{j i} * S_{j i}
$$

In the formula, the value range of the use proportion of the candidate green building materials was [0\%, 100\%], the corresponding constraint conditions can be expressed by Formula 14:

$$
0 \leq S_{j i} \leq 1 ; j \in N_{z}, i \in N_{s}
$$

For each type, the sum of use proportions of the candidate green building materials must be $100 \%$, the corresponding constraint conditions can be expressed by Formula 15:

$$
\sum_{i \in N_{s}} S_{i j}=1 ; j \in N_{z}, i \in N_{s}
$$

In order to ensure that the water saving rate reaches $80 \%$ while the construction cost is as low as possible, assuming the water saving rate or energy saving rate of a specific material is $\eta_{j i}$, then constraint conditions shown as Formula 16 can be constructed:

$$
\sum_{i \in N_{s}} S_{j i} * Q_{j i} * \eta_{j i} \leq 0.8 ; j \in N_{z}, i \in N_{s}
$$

Suppose that the determination of whether a specific material is a recycled material can be described by a binary function $Y_{j i-1}$; if it is a recycled material, then the value of $Y_{j i-1}$ takes 1 ; otherwise, its value is $0 . L_{j i}$ represents the unit weight of the material. In order to ensure that the weight of recycled green building materials accounts for more than $10 \%$ in the weight of candidate materials, a constraint condition shown as Formula 17 was constructed:

$$
\sum_{j \in N_{z}} \sum_{i \in N_{s}} S_{j i} * Q_{j i} * L_{j i} * Y_{j i-1} \geq 0.1
$$

Suppose that the determination of whether a specific material is a construction waste material can be described by a binary function $Y_{j i-2}$; if it is a construction waste material, then the value of $Y_{j i-2 c}$ takes 1 ; otherwise, its value is 0 . In order to ensure that the weight of construction waste materials accounts for more than $30 \%$ in the weight of candidate materials, a constraint condition shown as Formula 18 was constructed:

$$
\sum_{j \in N_{z}} \sum_{i \in N_{s}} Y_{j i-1} * Q_{j i} * L_{j i} * Y_{j i-2} \geq 0.3
$$

Suppose that the determination of whether a specific material is recyclable can be described by a binary function $Y_{j i-}$ ${ }_{3}$; if it is a recyclable material, then the value of $Y_{j i-3}$ takes 1 ; otherwise, its value is 0 . In order to ensure that the weight of recyclable materials accounts for more than $5 \%$ in the weight of candidate materials, a constraint condition shown as Formula 19 was constructed:

$$
\sum_{j \in N_{z}} \sum_{y \in N_{s}} Y_{j i-1} * Q_{j i} * L_{j i} * Y_{j i-3} \geq 0.05
$$

\section{MULTI-OBJECTIVE ENERGY-SAVING OPTIMIZATION DESIGN BASED ON THE APPLICATION OF GREEN BUILDING MATERIALS}

Based on the obtained green-level evaluation and optimization results of green building materials, we can perform dynamic energy-saving design on buildings with the change of time. The calculation and data analysis of the design process, as well as the input/output of the system, all change with the time, and they meet the multi-objective optimization laws at the same time. Figure 1 gives the flow of the multiobjective optimization algorithm for the energy-saving design of buildings. The specific steps are:

Step1: Make conditional assumptions, clarify the boundary of the building energy-saving design process, and calculate the construction cost based on each link of the production and use processes of green building materials. The construction cost of each link mainly includes the resource consumption cost, the energy consumption cost, and the environmental protection cost, and the corresponding calculations were completed within the specified inventory analysis time range. In the statistical stage, the calculated values of the construction cost of each link need to be discounted to the initial boundary of the time range of the inventory analysis. If the inventory analysis time range of each link belongs to the time range set by the evaluation strategy, then initial value of the environmental impact factors of each link is assumed as known. When the output of a previous link is the input of the next link, the cost of this link can be ignored.

Step2: Assume $b_{j i}$ represents the consumption of the $\mathrm{j}$-th resource or energy in the i-th link, $n_{l}$ represents the number of the resource or energy types, $m_{h}$ represents the number of links in the production and use processes of green building materials, then, the input process matrix could be constructed as Formula 20:

$$
B=\left[\begin{array}{cccc}
b_{11} & b_{12} & \ldots & b_{1 m_{h}} \\
b_{21} & b_{22} & \ldots & b_{2 m_{h}} \\
\cdots & \ldots & B_{j i} & \ldots \\
b_{n_{l} 1} & b_{n_{l} 2} & \cdots & b_{n_{l} m_{h}}
\end{array}\right]
$$

Step3: Assume $d_{x y}$ and $s$ represent the value and type of a factor related to environmental impact that appears in the $i-t h$ 
link but does not appear in the i+1-th link, then the output process matrix can be constructed as Formula 21:

$$
D=\left[\begin{array}{cccc}
d_{11} & d_{12} & \ldots & d_{1 m_{h}} \\
d_{21} & d_{22} & \ldots & d_{2 m_{h}} \\
\cdots & \cdots & d_{j i} & \ldots \\
d_{s 1} & d_{s 2} & \cdots & d_{s m_{h}}
\end{array}\right]
$$

Step4: Construct the summation matrix $E=(1,1, \ldots, 1,)^{T}$. The number of column vectors of the matrix that is subjected to the left multiplication operation with the summation matrix determines the number of the horizontal vectors of the matrix

Step5: Assume $e_{j 1}$ represents the unit cost of the $\mathrm{j}$-th resource or energy in $\mathrm{B}$, then the constructed input cost matrix can be expressed as $G=\left(g_{11}, g_{21}, \ldots, g_{j 1}, \ldots, g_{n l 1}\right)^{T}$. Assume $f_{j 1}$ represents the unit increased cost of the $\mathrm{j}$-th environmental impact factor in $\mathrm{D}$, then the output cost matrix can be constructed as $F=\left(f_{11}, f_{21}, \ldots, f_{j 1}, \ldots, f_{v 1}\right)^{T}$.

Step6: Assume $D V$ and $A V$ represent the discounted value and actual value of the future operating cost of the building, $\beta$ represents the benchmark discount rate of the production industry of green building materials, and the discount period is $\theta$ years; then the discounted value of the operating cost of the building can be calculated by the Formula 22 :

$$
D V=A V /(1+\beta)^{\theta}
$$

Step7: Construct model for the relationships between B, D and the operating cost of the building. Because the row vectors of the two process matrices have different links that have time span and different cost discount rates, it is necessary to introduce the same type matrix respectively. Suppose the duration of the $i$-th link is $T_{i}$, then, the introduced time coefficient matrix $H_{1}$ of $n_{l} \times m_{h}$ order can be described by Formula 23:

$$
H_{1}=\left[\begin{array}{cccc}
h_{1}^{T_{1}} & h_{1}^{T_{1}+T_{2}} & \ldots & h_{1}^{T_{1}+T_{2}+\ldots+T_{i}+\ldots+T_{m_{h}}} \\
h_{2}^{T_{1}} & h_{2}^{T_{1}+T_{2}} & \ldots & h_{2}^{T_{1}+T_{2}+\ldots+T_{i}+\ldots+T_{m_{h}}} \\
\ldots & \ldots & h_{j}^{T_{1}+T_{2}+\ldots+T_{i}} & \ldots \\
h_{n_{l}}^{T_{1}} & h_{n_{l}}^{T_{1}+T_{2}} & \ldots & h_{n_{l}}^{T_{1}+T_{2}+\ldots+T_{i}+\ldots+\ldots+T_{m_{h}}}
\end{array}\right]
$$

The time coefficient matrix $H_{2}$ of $n_{l} \times p$ order can be described by Formula 23 as:

$$
H_{2}=\left[\begin{array}{cccc}
h_{1}^{T_{1}} & h_{1}^{T_{1}+T_{2}} & \ldots & h_{1}^{T_{1}+T_{2}+\ldots+T_{x}+\ldots+T_{n_{l}}} \\
h_{2}^{t_{1}} & h_{2}^{T_{1}+T_{2}} & \ldots & h_{2}^{T_{1}+T_{2}+\ldots+T_{y}+\ldots+T_{n_{l}}} \\
\ldots & \ldots & h_{j}^{T_{1}+T_{2}+\ldots+T_{i}} & \ldots \\
h_{p}^{T_{1}} & h_{p}^{T_{1}+T_{2}} & \ldots & h_{p}^{T_{1}+T_{2}+\ldots+T_{y}+\ldots+\ldots+T_{m_{l}}}
\end{array}\right]
$$

It satisfies $\mathrm{h}=1 /(1+\beta)$.

Perform Hadamard product operation on $B$ and $H_{l}$, then there is:

$$
\begin{gathered}
B \times H_{1}=\left(b_{j i} \times h_{j}^{T_{1}+T_{2}+\ldots+T_{i}}\right)_{n_{l} \times m_{h}}=\left[\begin{array}{cccc}
b_{11} & b_{12} & \ldots & b_{1 m_{h}} \\
b_{21} & b_{22} & \ldots & b_{2 m_{h}} \\
\ldots & \ldots & b_{x y} & \ldots \\
b_{n_{l 1}} & b_{n_{l 2}} & \ldots & b_{n_{l 2} m_{h}}
\end{array}\right] * \\
{\left[\begin{array}{cccc}
h_{1}^{T_{1}} & h_{1}^{T_{1}+T_{2}} & \ldots & h_{1}^{T_{1}+T_{2}+\ldots+T_{j}+\ldots+T_{m_{h}}} \\
h_{2}^{T_{1}} & h_{2}^{T_{1}+T_{2}} & \ldots & h_{2}^{T_{1}+T_{2}+\ldots+T_{j}+\ldots+T_{m_{h}}} \\
\ldots & \ldots & h_{j}^{T_{1}+T_{2}+\ldots+T_{i}} & \ldots \\
h_{n_{l}}^{T_{1}} & h_{n_{l}}^{T_{1}+T_{2}} & \ldots & h_{n_{l}}^{T_{1}+T_{2}+\ldots+T_{j}+\ldots+\ldots+T_{m_{h}}}
\end{array}\right]}
\end{gathered}
$$

Perform Hadamard product operation on $D$ and $H_{2}$, then there is:

$$
\begin{gathered}
D \times H_{2}=\left(d_{j i} \times h_{j}^{T_{1}+T_{2}+\ldots+T_{i}}\right)_{p \times n_{l}}=\left[\begin{array}{cccc}
d_{11} & d_{12} & \ldots & d_{1 n_{l}} \\
d_{21} & d_{22} & \ldots & d_{2 n_{l}} \\
\ldots & \ldots & d_{x y} & \ldots \\
d_{p_{1}} & d_{p_{2}} & \ldots & d_{p n_{l}}
\end{array}\right] * \\
{\left[\begin{array}{cccc}
h_{1}^{T_{1}} & h_{1}^{T_{1}+T_{2}} & \ldots & h_{1}^{T_{1}+T_{2}+\ldots+T_{j}+\ldots+T_{n_{l}}} \\
h_{2}^{T_{1}} & h_{2}^{T_{1}+T_{2}} & \ldots & h_{2}^{T_{1}+T_{2}+\ldots+T_{j}+\ldots+T_{n_{l}}} \\
\ldots & \ldots & h_{j}^{T_{1}+T_{2}+\ldots+T_{i}} & \ldots \\
h_{p}^{T_{1}} & h_{p}^{T_{1}+T_{2}} & \ldots & h_{p}^{T_{1}+T_{2}+\ldots+T_{j}+\ldots+\ldots+T_{n_{l}}}
\end{array}\right]}
\end{gathered}
$$

In this paper, the matrices $G$ and $F$ were converted from $n_{l} \times 1$ order and $m_{h} \times 1$ order to $n_{l} \times m_{h}$ order and $p \times m_{h}$ order as shown in Formula 27. The purpose is to satisfy the requirements of the Hadamard product same-type matrix:

$$
\left\{\begin{aligned}
G^{\prime} & =\left[\begin{array}{llll}
g_{11}^{1} & g_{11}^{2} & \cdots & g_{11}^{m_{h}} \\
g_{21}^{1} & g_{21}^{2} & \cdots & g_{21}^{m_{h}} \\
\cdots & \cdots & g_{j 1}^{i} & \cdots \\
g_{n_{l} 1}^{1} & g_{n_{l} 1}^{2} & \cdots & f_{n_{l} 1}^{m_{h}}
\end{array}\right] \\
F^{\prime}= & {\left[\begin{array}{llll}
f_{11}^{1} & f_{11}^{2} & \cdots & f_{11}^{m_{h}} \\
f_{21}^{1} & f_{21}^{2} & \cdots & f_{21}^{m_{h}} \\
\cdots & \cdots & f_{j 1}^{i} & \cdots \\
f_{p 1}^{1} & f_{p 1}^{2} & \cdots & f_{p 1}^{m_{h}}
\end{array}\right] }
\end{aligned}\right.
$$

The $m_{h} \times 1$-order total construction cost matrix $C M_{\text {Total }}$ can be calculated by Formula 28:

$$
\begin{aligned}
& C M_{\text {Total }}=\left[\left(B * H_{1}\right) * G^{\prime}\right]^{T} D_{n_{l} \times 1} \\
& +\left[\left(D * H_{2}\right) * F^{\prime}\right]^{T} E_{p \times 1}
\end{aligned}
$$

It can be seen from the above formula that each row vector of $C M_{\text {Total }}$ is the increased cost $C M_{m h}$ of the corresponding link and the factor related to environmental impact, therefore, the cost of the production and use processes of green building materials can be expressed as $\sum_{j=1}^{m h} C M_{T j}$. 
Step8: Combine with the genetic algorithm to obtain the multi-objective optimization results of building energy-saving design. First, adopt random ergodic selection to perform coding operations on the optimization factors related environmental impact, perform random discrete recombination on individuals selected from the generated population, and determine the crossover recombination rate of the genetic algorithm. Then, within the evaluation intervals of each optimization factor related to environmental impact, perform mutation operations and determine the mutation rate of the genetic algorithm. After that, execute the algorithm until the number of iterations reaches the preset maximum value and terminate the calculation.

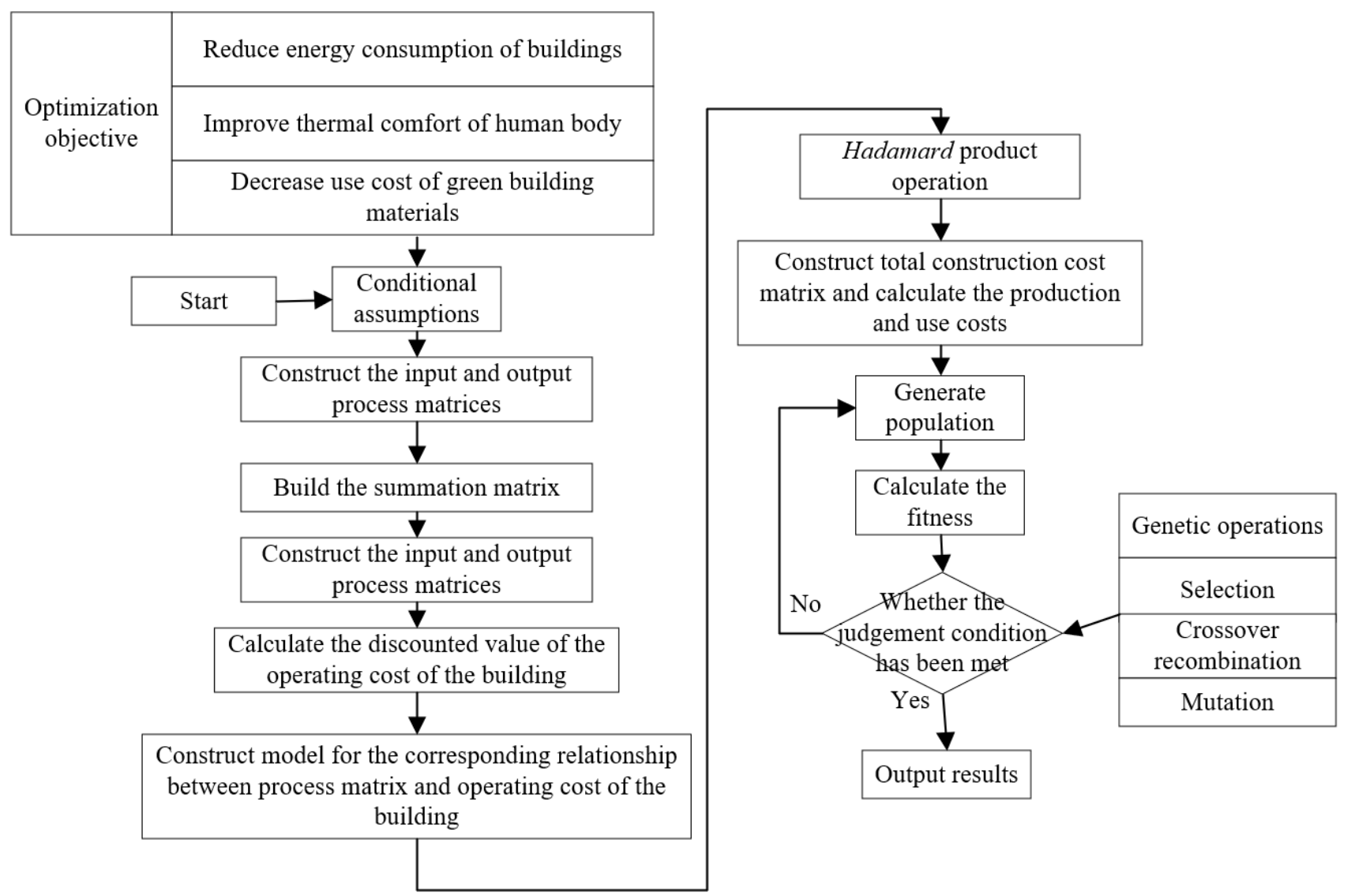

Figure 1. Flow of multi-objective optimization algorithm for building energy-saving design

\section{EXPERIMENTAL RESULTS AND ANALYSIS}

Combining with the quantitative analysis of environmental impact factors of green building materials and the understanding of green-level evaluation indexes of the materials, this paper extracted the related quantifiable indexes of green building materials from the evaluation index system, and listed the evaluation scoring requirements of different green levels. Table 3 shows the green levels of green building materials and scores of environmental impact factors. According to the table, the extracted quantifiable indexes included all the terms related to environmental protection in the evaluation index system, which can better reflect the green levels of the candidate green building materials.

Table 3. Green levels of green building materials and scores of environmental impact factors

\begin{tabular}{|c|c|c|c|c|c|c|c|}
\hline & $\begin{array}{c}\text { Factors related } \\
\text { to resource } \\
\text { consumption }\end{array}$ & $\begin{array}{c}\text { Factors } \\
\text { related to } \\
\text { energy } \\
\text { consumption }\end{array}$ & $\begin{array}{l}\text { Factors } \\
\text { related to } \\
\text { global } \\
\text { warming }\end{array}$ & $\begin{array}{c}\text { Factors } \\
\text { related to } \\
\text { acidification } \\
\text { effect }\end{array}$ & $\begin{array}{c}\text { Factors related to } \\
\text { ozone depletion } \\
\text { and } \\
\text { photochemical } \\
\text { smog }\end{array}$ & $\begin{array}{l}\text { Factors related } \\
\text { to water body } \\
\text { eutrophication }\end{array}$ & $\begin{array}{l}\text { Number } \\
\text { of terms }\end{array}$ \\
\hline Level 1 & 4 & 3 & 2 & 2 & 4 & 1 & 16 \\
\hline Level 2 & 5 & 4 & 3 & 3 & 5 & 2 & 22 \\
\hline Level 3 & 6 & 5 & 4 & 4 & 6 & 3 & 28 \\
\hline $\begin{array}{l}\text { Candidate- } \\
\text { related } \\
\text { terms }\end{array}$ & 4 & 2 & 2 & 3 & 6 & 2 & 19 \\
\hline Total score & 7 & 6 & 5 & 6 & 8 & 6 & 38 \\
\hline
\end{tabular}




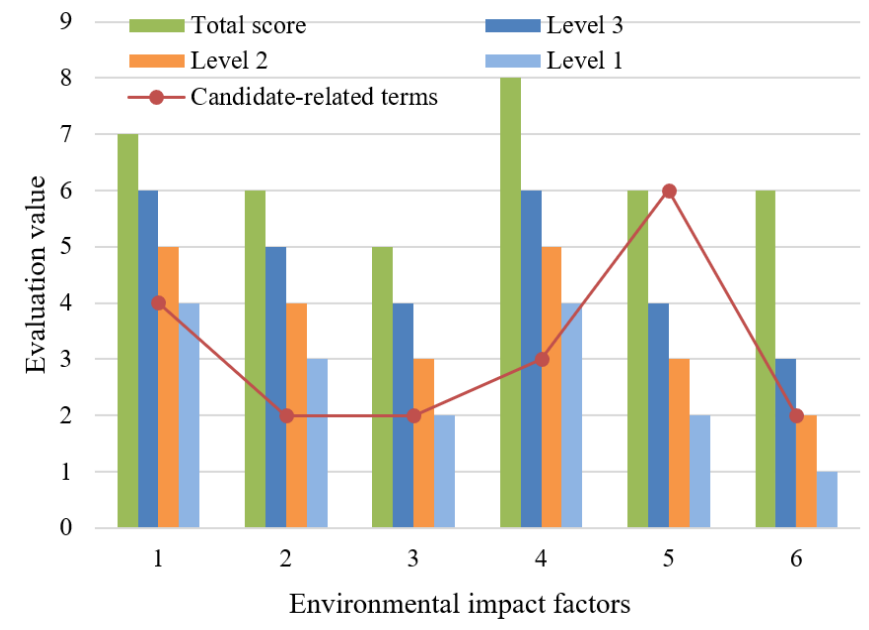

Figure 2. Increased costs of environmental impact factors of green building materials

In order to verify the effectiveness of the constructed optimization selection model of green building materials, this paper calculated the environmental impact factors and the increased costs of the candidate green building materials, and the calculation results are given in Figure 2. According to the figure, green building materials with a green level of level-3 outperformed level-2 and level-1 green building materials in terms of evaluations of all environmental impact factors (namely factors related to resource consumption, energy consumption, global warming, ozone depletion \& photochemical smog, acidification effect, and water body eutrophication), which had further verified that the green levels of green building materials classified based on the quantitative analysis of environmental impact factors were scientific. This paper selected building green materials with higher green levels for the energy-saving design of buildings. Before the design, all candidate materials were re-sorted according to the use cost and green-level evaluation, and the accumulated increased use cost of the materials and the accumulated increased green level of factors were calculated. Figure 3 gives the use costs of 20 candidate materials and their green-level evaluation results; Figure 4 gives the relationship between the accumulated use cost of a certain material and its accumulated green level.

According to the figure, if we want to achieve a green level of about 8-9, it only needs to increase the input cost by not more than 1.1 million yuan; but if we want to achieve a green level of about 10-11, the increased input cost is about 1.55-165 million yuan, and this money for a green level of 11 is as high as 4.5 million yuan or more. Under the three constraints of a weight proportion of recycled green building materials of more than $10 \%$, a weight proportion of construction waste materials of more than $30 \%$, and a weight proportion of recyclable green building materials of more than $5 \%$, the additional cost was minimized to complete the optimization selection of the candidate green building materials.

The multi-objective optimization results of building energysaving design before and after the optimization selection of green building materials were summarized, and Figures 5-8 respectively give the change curves of the objective function of building energy-saving design, the change curves of building energy consumption, the change curves of building heat loss, and the change curves of construction cost. According to Figure 5, when the green level is set as 8, after 100 iterations, the value of the objective function of building energy-saving design approaches the ideal value faster.

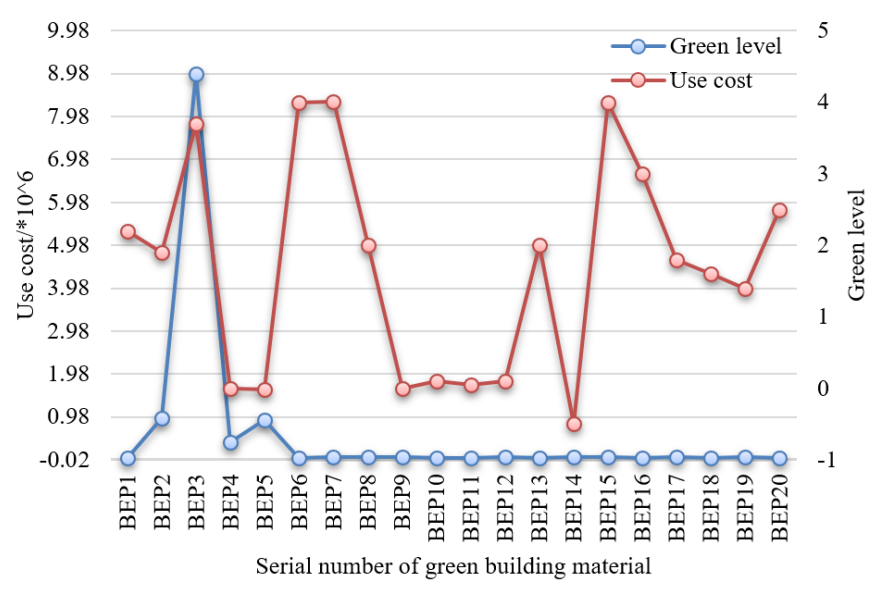

Figure 3. Use costs of 20 candidate materials and green-level evaluation results

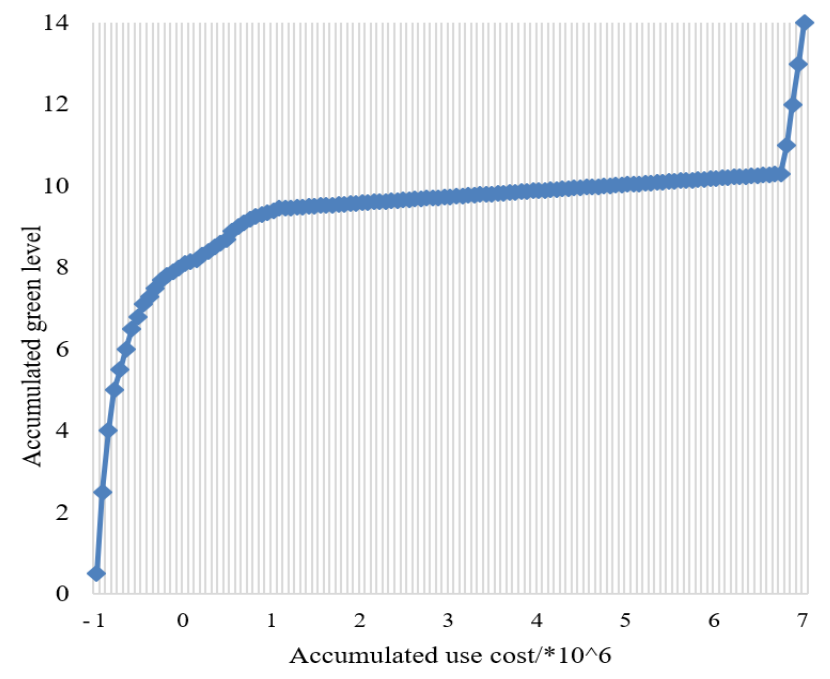

Figure 4. Relationship between accumulated use cost of a certain material and its accumulated green level

According to Figures 6 and 7, after 100 iterations, when the green level was 8 , the energy consumption and heat loss of the building reached the minimum and the indoor thermal comfort of human body reached the optimal effect. According to Figure 8, compared with situations of other green levels, when the green level was 8 , the construction cost, energy consumption of the building, and the thermal comfort all reached the optimal states. Therefore, the proposed green building material optimization selection strategy provided certain reference for the multi-objective optimization of the energy-saving design of buildings, the three were balanced to reach the ideal state. 


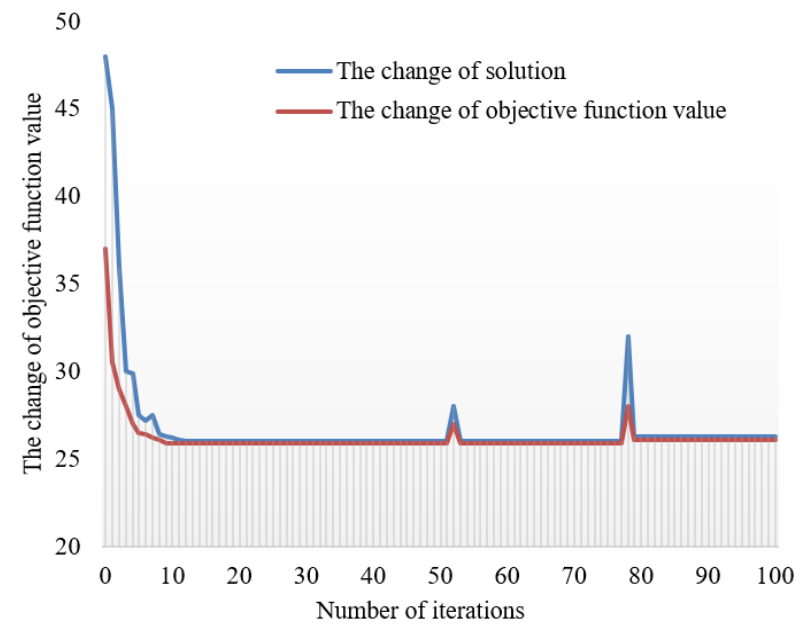

(a)

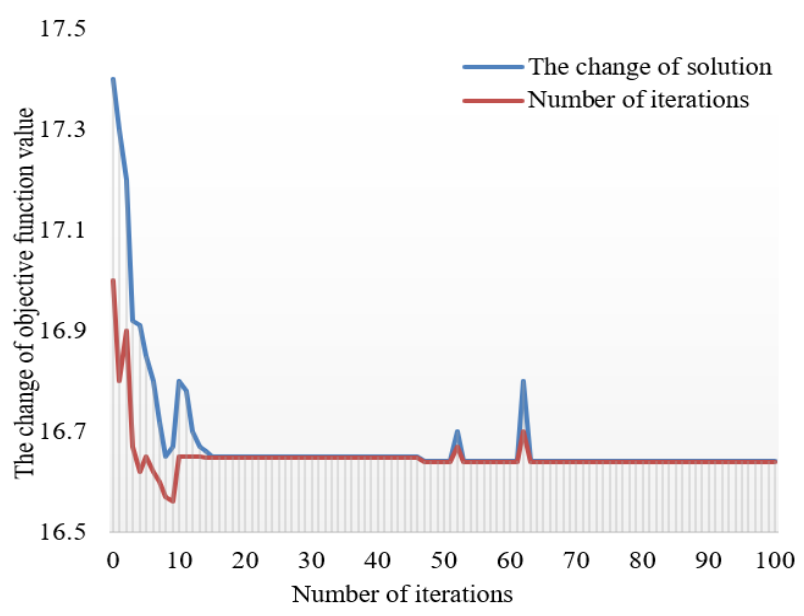

(b)

Figure 5. Change curves of the objective function of building energy-saving design before and after the optimization selection of green building materials

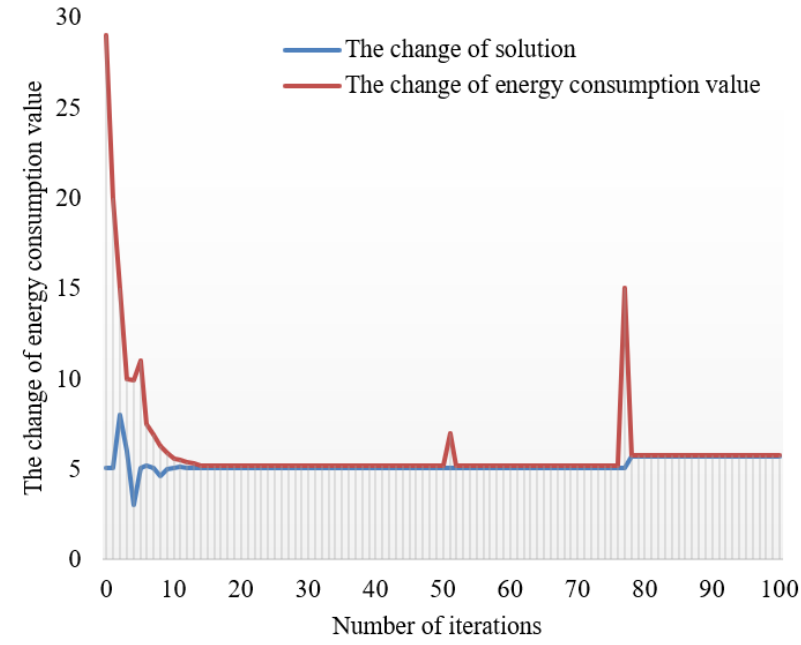

(a)

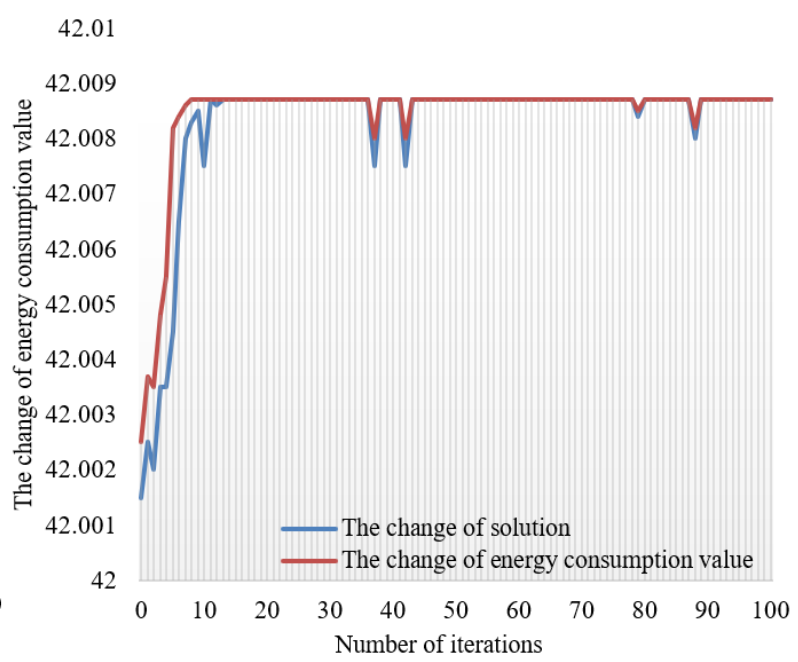

(b)

Figure 6. Change curves of building energy consumption before and after the optimization selection of green building materials

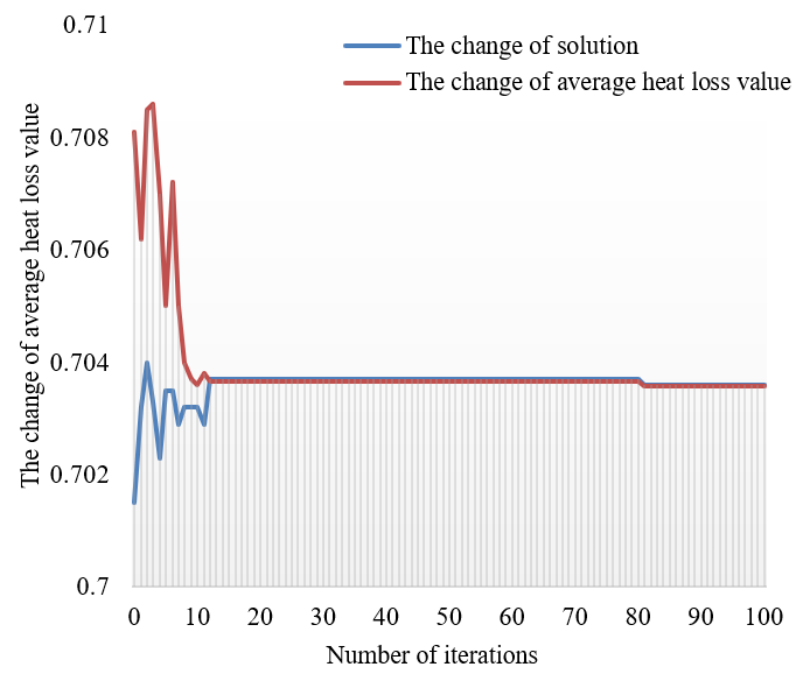

(a)

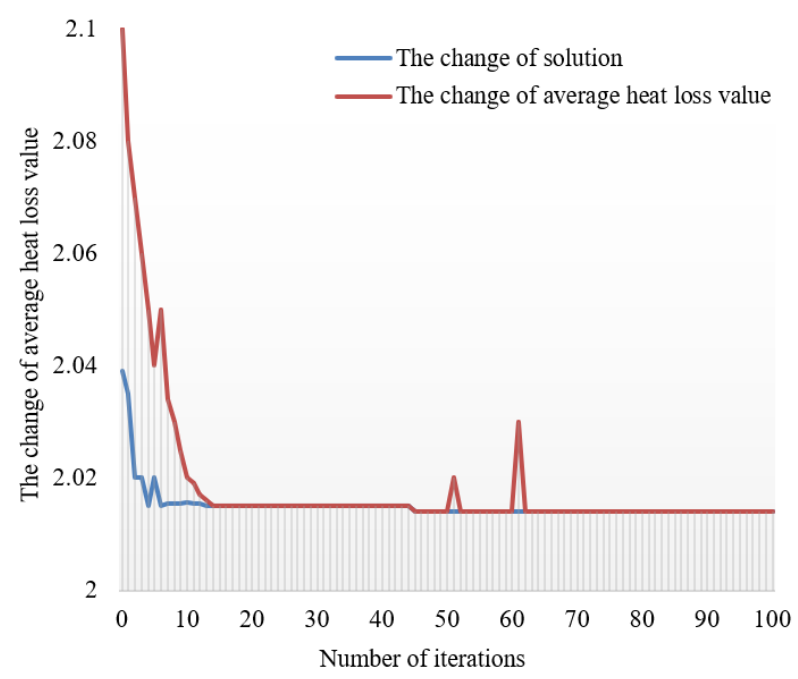

(b)

Figure 7. Change curves of building heat loss before and after the optimization selection of green building materials 


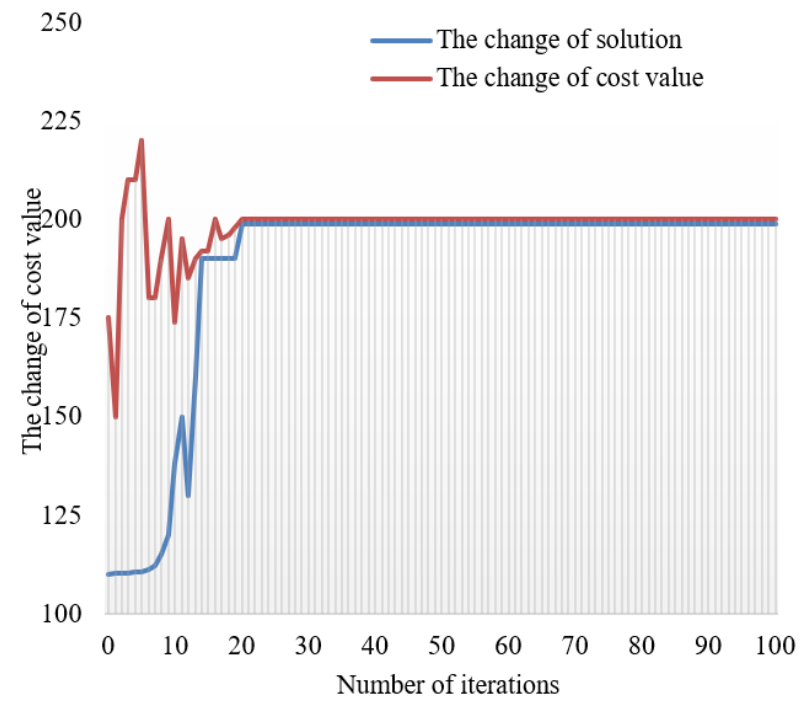

(a)

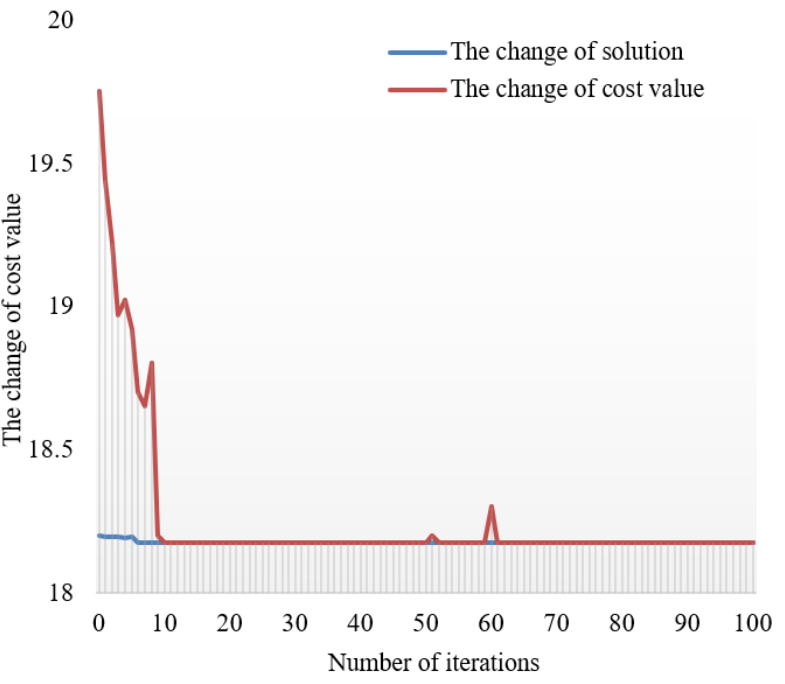

(b)

Figure 8. Change curves of construction cost before and after the optimization selection of green building materials

\section{CONCLUSION}

This study carried out building energy-saving design and multi-objective optimization based on the application of green building materials. First, this paper elaborated the quantification method for the environmental impact factors of green building materials, analyzed the green-level evaluation of green building materials based on calculation results, and proposed the quantitative evaluation intervals and standards of green building materials. Then, experimental results had verified that the extracted quantifiable evaluation indexes can well indicate the green levels of the candidate green building materials. After that, the paper constructed an optimization selection model for green building materials, and gave the multi-objective optimization algorithm of the energy-saving design of buildings and the specific algorithm flow. The proposed green building material optimization selection strategy provided certain reference for the multi-objective optimization of the energy-saving design of buildings, it balanced the construction cost, the energy consumption of buildings, and the thermal comfort, and reached an ideal state.

\section{ACKNOWLEDGMENT}

This work was supported by the Research on the precise service docking between Hebei Vocational Colleges and the Grand Canal cultural tourism brand construction, Research topics of social science development in Hebei Province (Grant No.: 20200403113).

\section{REFERENCES}

[1] Moon, A.S., Patel, A. (2021). Sustainable construction using eps beads in light weight blocks to form innovative foam concrete as a green building material. In IOP Conference Series: Materials Science and Engineering, 1017(1): 012009. https://doi.org/10.1088/1757899X/1017/1/012009

[2] Khoshnava, S.M., Rostami, R., Valipour, A., Ismail, M., Rahmat, A.R. (2018). Rank of green building material criteria based on the three pillars of sustainability using the hybrid multi criteria decision making method. Journal of Cleaner Production, 173: 82-99. https://doi.org/10.1016/j.jclepro.2016.10.066

[3] Wizaka, W., Nurdiani, N. (2017). Improving student's technical drawing in building technology course with shared and digital enrichment material in order to support green technology. In IOP Conference Series: Earth and Environmental Science, 109(1): 012047. https://doi.org/10.1088/1755-1315/109/1/012047

[4] Yudelson, J. (2010). The green building revolution. Island Press.

[5] Aryaningrum, D.E., Latief, Y., Riantini, L.S., Susilo, B. (2018). Development of implementation guidlines for maintenance, repairation and determine material spesifications for mechanical component design in government own green building based on work breakdown structure. In MATEC Web of Conferences, 206: 02014. https://doi.org/10.1051/matecconf/201820602014

[6] Charai, M., Sghiouri, H., Mezrhab, A., Karkri, M. (2021) Thermal insulation potential of non-industrial hemp (Moroccan cannabis sativa L.) fibers for green plasterbased building materials. Journal of Cleaner Production, 292:

126064. https://doi.org/10.1016/j.jclepro.2021.126064

[7] Cammarano, S., Pellegrino, A., Verso, V.R.L., Aghemo, C. (2015). Daylighting design for energy saving in a building global energy simulation context. Energy Procedia, $78:$ 364-369. https://doi.org/10.1016/j.egypro.2015.11.672

[8] Echeverria, C.A., Ozkan, J., Pahlevani, F., Willcox, M., Sahajwalla, V. (2021). Effect of hydrothermal hotcompression method on the antimicrobial performance of green building materials from heterogeneous cellulose wastes. Journal of Cleaner Production, 280: 124377. https://doi.org/10.1016/j.jclepro.2020.124377

[9] Andreeva, K.A., Zakreskaya, L.V., Lubin, P.A., Abramov, M.V., Gandelsman, I.A. (2020). New materials for green building. Materials Science Forum, 974: 
https://doi.org/10.4028/www.scientific.net/MSF.974.44 6

[10] Sakthieswaran, N., Sophia, M. (2020). Prosopis juliflora fibre reinforced green building plaster materials-An eco-friendly weed control technique by effective utilization. Environmental Technology \& Innovation, 20: 101158. https://doi.org/10.1016/j.eti.2020.101158

[11] Sang, P.F., Xie, J.C., Liu, J.P., Liu, D.H., Cui, Y.P. (2020). Thermal design of rural energy-saving buildings in Qinghai based on non-balanced insulation theory. Acta Energiae Solaris Sinica, 41(3): 311-318.

[12] Zhang, K. (2020). Energy-saving parameterized design of buildings based on genetic algorithm. International Journal of Building Pathology and Adaptation, 38(5): 785-795. https://doi.org/10.1108/IJBPA-05-2019-0050

[13] Nguyen, D.H., Funabashi, T. (2019). Decentralized control design for user comfort and energy saving in multi-zone buildings. Energy Procedia, 156: 172-176. https://doi.org/10.1016/j.egypro.2018.11.123

[14] Al-Atesh, E., Rahmawati, Y., Zawawi, N.A.W.A. (2021). Sustainability criteria for green building material selection in the malaysian construction industry. In Proceedings of the International Conference on Civil, Offshore and Environmental Engineering, pp. 693-700. https://doi.org/10.1007/978-981-33-6311-3_79

[15] Lee, D.H. (2020). Establishment a recycled green building material model for use in the construction industry in global circular economies. In IOP Conference Series: Earth and Environmental Science, 410(1): 012011. $1315 / 410 / 1 / 012011$

[16] Jexembayeva, A., Salem, T., Jiao, P., Hou, B., Niyazbekova, R. (2020). Blended cement mixed with basic oxygen steelmaking slag (BOF) as an alternative green building material. Materials, 13(14): 3062. https://doi.org/10.3390/ma13143062

[17] Kaur, M., Singh, J., Kaur, M. (2018). Hypo sludge-A green building material. In International Conference on Sustainable Waste Management through Design, pp. 512-521. https://doi.org/10.1007/978-3-030-02707-0_58

[18] Hong, S.H., Lee, S.K., Yu, J.H. (2019). Automated management of green building material information using web crawling and ontology. Automation in Construction, 102: 230-244. https://doi.org/10.1016/j.autcon.2019.01.015
[19] Dzulkifli, N.A., Omar, R.C., Abidin, A.H.Z., Roslan, R., Wahab, W.A., Baharuddin, I.N.Z., Sanusi, K.A. (2019). An innovative green material for reducing the urban heat island surrounding PMU towards smart low carbon building and city. International Journal of Advanced Science and Technology, 28(10): 247-254.

[20] Castaldo, V.L., Pisello, A.L., Piselli, C., Fabiani, C., Cotana, F., Santamouris, M. (2018). How outdoor microclimate mitigation affects building thermal-energy performance: A new design-stage method for energy saving in residential near-zero energy settlements in Italy. Renewable Energy, 127: 920-935. https://doi.org/10.1016/j.renene.2018.04.090

[21] Cao, J., Li, M., Wang, M., Xiong, M., Meng, F. (2017). Effects of climate change on outdoor meteorological parameters for building energy-saving design in the different climate zones of China. Energy and buildings, 146: 65-72. https://doi.org/10.1016/j.enbuild.2017.04.045

[22] Berseneva, M., Vasilovskaya, G., Danchenko, T., Inzhutov, I., Amelchugov, S., Yakshina, A., Danilovich, H. (2018). Energy-saving technologies in design and construction of residential buildings and industrial facilities in the far North. In Energy Management of Municipal Transportation Facilities and Transport, pp. 59-68. https://doi.org/10.1007/978-3-030-19756-8_6

[23] Ilham, R.M., Latief, Y., Riantini, L.S., Susilo, B. (2018). Development of maintenance-reparation guidance, and material specification for green building's electrical component in government building based on work breakdown structure (WBS). In IOP Conference Series: Materials Science and Engineering, 446(1): 012005. https://doi.org/10.1088/1757-899X/446/1/012005

[24] Pioppi, B., Piselli, C., Crisanti, C., Pisello, A.L. (2020). Human-centric green building design: the energy saving potential of occupants' behaviour enhancement in the office environment. Journal of Building Performance Simulation, 13(6): 621-644. https://doi.org/10.1080/19401493.2020.1810321

[25] Echeverria, C.A., Ozkan, J., Pahlevani, F., Willcox, M., Sahajwalla, V. (2021). Effect of hydrothermal hotcompression method on the antimicrobial performance of green building materials from heterogeneous cellulose wastes. Journal of Cleaner Production, 280: 124377. https://doi.org/10.1016/j.jclepro.2020.124377 